\title{
HUBUNGAN PENGETAHUAN REMAJA TENTANG DAMPAK SEKS BEBAS BAGI KESEHATAN REPRODUKSI
}

\section{TEENAGER KNOWLEDGE OF THE IMPACT OF FREE SEX ON REPRODUCTIVE HEALTH}

\author{
Nurin Fauziyah ${ }^{1, *}$, Eva Nur Azizah ${ }^{2}$ \\ 1,2, STIKes Pamenang \\ *Korespondensi penulis : nurinfauziah.nf@gmail.com
}

\begin{abstract}
Abstrak
Kematangan seksual pada remaja menyebabkan munculnya minat seksual dan keinginan remaja tentang seksual sehingga dapat mengakibatkan dampak yang negatif terhadap pergaulan remaja yang berdampak pada seks bebas. Seks bebas mempunyai resiko yang sangat besar terhadap remaja. Dampak seks bebas remaja antara lain kehamilan diluar nikah, terinfeksi penyakit menular seksual (PMS) dan gangguan psikologi remaja. Tujuan penelitian adalah untuk mengetahui Pengetahuan Remaja Tentang Seks Bebas Bagi Kesehatan Reproduksi. Desain penelitian menggunakan desain diskriptif. Populasi penelitian adalah siswa-siswi kelas IX Di SMPN I Plemahan Kabupaten Kediri Tahun 2019. Teknik pengumpulan data menggunakan kuesioner. Analisa data dilakukan secara diskriptif. Hasil penelitian menunjukkan sebagian besar responden (32 orang $140 \%$ ) responden memiliki pengetahuan cukup; dan sebagian kecil yaitu 3 responden $(3,75)$ memiliki pengetahuan kurang. Kesimpulan dari penelitian ini adalah sebagian besar remaja memiliki tingkat pengetahuan tentang seks bebas pada level cukup. Dari hasil penelitian disarankan untuk diselenggarakan penelitian lanjutan untuk mengetahui faktor yang mempengaruhi pengetahuan tentang seks bebas.
\end{abstract}

Kata kunci: Pengetahuan, Remaja, Dampak Seks Bebas, Kesehatan Reproduksi.

\begin{abstract}
Sexual maturity in adolescents leads to the emergence of sexual interest and desire for adolescents about sexuality so that it can have a negative impact on adolescent relationships that impact on free sex. Free sex has a very big risk to adolescents. The impact of adolescent free sex includes pregnancy outside of marriage, being infected with sexually transmitted diseases (STDs) and adolescent psychological disorders. The aim of this research was to know the knowledge of adolescents about free sex for reproductive health The research design used a descriptive design. The research population was class IX students at SMPN I Plemahan Kediri Regency in 2019. The data collection technique used a questionnaire. Data analysis was carried out descriptively. The results showed that most of the respondents (32 people /40\%) had sufficient knowledge; and a small proportion, namely 3 respondents (3.75) had less knowledge. The conclusion of this study is that most adolescents have a sufficient level of knowledge about free sex. From the research results, it is suggested to conduct further research to determine the factors that influence knowledge about free sex.
\end{abstract}

Key words: Knowledge, Teenagers, The Impact of Free Sex, Reproduction Health.

\section{Pendahuluan}

Kemudahan dalam menemukan berbagai macam informasi termasuk informasi yang berkaitan dengan masalah seks, merupakan salah satu faktor yang bisa menjadikan remaja terjebak dalam perilaku seks yang tidak sehat (Heriana, 2012). Berbagai informasi bisa diakses oleh para remaja melalui internet atau majalah yang disajikan baik secara jelas dan secara mentah yaitu hanya mengajarkan cara-cara seks tanpa ada penjelasan mengenai perilaku seks yang sehat dan dampak seks yang berisiko, misalnya penyakit yang diakibatkan oleh perilaku seks yang tidak sehat (Bowden Jan \& Vicky Manning, 2011). Hasil dari studi 
pendahuluan yang dilaksanakan di SMPN I Plemahan Kabupaten Kediri pada tanggal Januari 2019, didapatkan dari 10 siswa-siswi SMPN I Plemahan Kabupaten Kediri memiliki pengetahuan yang kurang akan kesehatan reproduksi yang berkaitan dengan perilaku seks bebas. Cara yang digunakan yaitu wawancara dan didapatkan 4 anak $(40 \%)$ remaja yang pernah berpacaran dan berpegangan tangan, 3 anak (30\%) remaja yang pernah melakukan ciuman, 2 anak (20\%) pernah berpelukan, 1 anak $(10 \%)$ pernah melakukan oral seks dan tidak ada remaja yang pernah melakukan hubungan kelamin, dan kesemuanya tidak mengerti akan dampak seks bebas bagi kesehatan reproduksinya. Penyebab dari remaja melakukan tindakan seperti itu karena dasar keingintahuan dan ketidaktahuan remaja tentang dampak seks bebas dan kurangnya pengetahuan remaja tentang seks bebas dan remaja belum pernah mendapatkan penyuluhan tentang seks bebas atau pendidikan seksual remaja.

Mengingat permasalahan tentang seks bebas dikalangan remaja, maka sebagai upaya untuk memberitahukan dampak negatif yang dapat terjadi perlu dilakukan program pendidikan seks kepada remaja untuk mengetahui akibat dari seks bebas terhadap kesehatan reproduksinya, selain memberikan pendidikan seks kepada remaja, anak-anak muda diberdayakan untuk membuat keputusan yang aman terkait kesehatan seksual mereka dan diajarkan menjadi pribadi yang bertanggung jawab. Penyuluhan dari tenaga kesehatan kepada remaja yang dilakukan melalui kegiatan Usaha Kesehatan Sekolah (UKS), Pembinaan kepada kelompok remaja melalui karang taruna, Remaja Masjid dan lain-lain. Oleh karena itu sangat diperlukan pendidikan tentang pengetahuan seksual pada remaja di usia dini untuk menghindari terjadinya seks bebas atau dampak yang tidak diinginkan terjadi pada remaja.

\section{Metode}

Desain penelitian yang dipakai dalam penelitian ini adalah desain diskriptif. Dalam penelitian ini peneliti akan menggambarkan pengetahuan remaja tentang dampak seks bebas bagi kesehatan reproduksi di SMPN I Plemahan Kabupaten Kediri Tahun 2019.

Variabel dalam penelitian ini adalah pengetahuan remaja tentang seks bebas.
Populasi dalam penelitian ini adalah seluruh siswa-siswi kelas IX di SMPN I Plemahan Kabupaten Kediri, sejumlah 80 responden. Penelitian dilakukan pada seluruh populasi (total sampling). Analisis data dilakukan secara deskriptif.

\section{Hasil}

1. Data Umum

a. Karakteristik responden berdasarkan umur.

Tabel 1.1 Distribusi Frekuensi Berdasarkan Umur Di Kelas IX Di SMPN I Plemahan Kabupaten Kediri Tahun 2019.

\begin{tabular}{|l|l|l|l|}
\hline No & Umur & N & Prosentase (\%) \\
\hline 1 & $14-15$ tahun & 13 & 20 \\
\hline 2 & $16-17$ tahun & 65 & 75 \\
\hline 3 & $18-20$ tahun & 2 & 5 \\
\hline & Jumlah & 80 & 100 \\
\hline
\end{tabular}

b. Karakteristik responden berdasarkan jenis kelamin.
Tabel 1.2 Distribusi
Frekuensi

Berdasarkan Jenis Kelamin Di Kelas IX Di SMPN I Plemahan Kabupaten Kediri Tahun 2019.

\begin{tabular}{|l|l|l|l|}
\hline No & Jenis kelamin & $\mathrm{N}$ & $\begin{array}{l}\text { Prosentase } \\
(\%)\end{array}$ \\
\hline 1 & Laki-laki & 30 & 37,5 \\
\hline 2 & Perempuan & 50 & 62,5 \\
\hline & Jumlah & 80 & 100 \\
\hline
\end{tabular}

c. Karakteristik responden menurut pengalaman mendapatkan informasi.

Tabel 1.3 Distribusi Frekuensi Berdasarkan Pernah Mendapat Informasi Di SMPN I Plemahan Kabupaten Kediri Tahun 2019

d. Karakteristik reponden berdasarkan sumber informasi.

Tabel 1.4 Distribusi Frekuensi Berdasarkan

\begin{tabular}{|l|l|l|l|}
\hline No & $\begin{array}{l}\text { Pernah } \\
\text { mendapat } \\
\text { informasi }\end{array}$ & N & $\begin{array}{l}\text { Prosentase } \\
(\%)\end{array}$ \\
\hline 1 & Ya & 80 & 100 \\
\hline 2 & Tidak & 0 & 0 \\
\hline & Jumlah & 80 & 100 \\
\hline
\end{tabular}

Sumber Informasi Di SMPN I Plemahan Kabupaten Kediri Tahun 2019. 


\begin{tabular}{|l|l|l|l|}
\hline No & $\begin{array}{l}\text { Sumber } \\
\text { informasi }\end{array}$ & N & $\begin{array}{l}\text { Prosentase } \\
(\%)\end{array}$ \\
\hline 1 & $\begin{array}{l}\text { Tenaga } \\
\text { kesehatan }\end{array}$ & 6 & 7,5 \\
\hline 2 & $\begin{array}{l}\text { Lingkungan } \\
\text { sekolah }\end{array}$ & 50 & 62,5 \\
\hline 3 & $\begin{array}{l}\text { Lingkungan } \\
\text { keluarga }\end{array}$ & 10 & 12,5 \\
\hline 4 & Media massa & 14 & 17,5 \\
\hline & Jumlah & 80 & 100 \\
\hline
\end{tabular}

\section{Data Khusus}

Pada data khusus menggambarkan hasil penelitian tentang Pengetahuan Remaja Tentang Seks Bebas Bagi Kesehatan Reproduksi di Kelas IX Di SMPN I Plemahan Kabupaten Kediri Tahun 2019 yang dapat dilihat tabel berikut ini :

Tabel 2.1 Pengetahuan Remaja Tentang Dampak Seks Bebas Bagi Kesehatan Reproduksi Di SMPN I Plemahan Kabupaten Kediri Tahun 2019.

\begin{tabular}{|l|l|l|l|}
\hline No & Pengetahuan & N & $\begin{array}{l}\text { Prosentase } \\
(\%)\end{array}$ \\
\hline 1 & Sangat baik & 23 & 28,75 \\
\hline 2 & Baik & 22 & 27,5 \\
\hline 3 & Cukup & 32 & 40 \\
\hline 4 & Kurang & 3 & 3,75 \\
\hline & Jumlah & 80 & 100 \\
\hline
\end{tabular}

Berdasarkan tabel 2.1 diatas dapat diketahui sebagian besar responden mempunyai pengetahuan Cukup Baik yaitu 32 responden (40\%) dan sebagian kecil mempunyai pengetahuan Kurang Baik yaitu sebanyak 3 responden $(3,75 \%)$. Dari 20 soal kuesioner yang dibahas tentang dampak seks bebas bagi kesehatan reproduksi didapatkan beberapa siswa-siswi yang belum mengerti tentang dampak seks bebas tersebut, remaja belum mengetahui tentang kehamilan di usia remaja dapat beresiko menimbulkan kematian ibu. Dari 80 responden hanya 16 responden (20\%) yang mengerti tentang dampak yang terjadi pada kehamilan remaja, selain kehamilan yang tidak dikehendaki pada remaja penyakit sifilis, herpes pada alat kelamin dan HIV/AIDS merupakan kelompok penyakit menular seksual (PMS) yang diakibatkan dari dampak seks bebas. Dari 80 responden hanya 40 responden $(50 \%)$ yang mengerti dan seks bebas juga bisa berdampak pada keadaan psikologi remaja hanya 46 responden $(57,5 \%)$.
Dari hasil penelitian didapatkan hasil yang sangat sedikit tentang pengetahuan responden tentang dampak seks bebas sehingga peneliti dapat menyimpulkan bahwa pengetahuan siswa - siswi masih cukup baik tentang dampak seks bebas bagi kesehatan reproduksi.

\section{Pembahasan}

Mayoritas remaja pernah mendapatkan informasi dan sumber informasi hanya dari lingkungan sekolah $(62,5 \%)$ sedangkan yang dari tenaga kesehatan lebih sedikit (6\%), sehingga perlu berkerja sama dengan institusi kesehatan agar pengetahuan remaja tentang dampak seks bebas bagi kesehatan reproduksi lebih luas lagi dan remaja juga dapat mengerti tentang cara merawat atau menjaga kesehatan reproduksi. Dari hasil penelitian didapatkan pengetahuan yang kurang akan dampak seks bebas sejumlah $3.7 \%$ yang sangat sedikit tentang pengetahuan responden tentang dampak seks bebas. Dampak yang dapat terjadi pada usia remaja yaitu kehamilan diluar nikah atau kehamilan yang tidak dikehendaki. Hamil dan melahirkan dalam usia remaja merupakan salah satu faktor risiko kehamilan yang tidak jarang membawa kematian ibu. Terjadinya perdarahan pada trimester pertama dan ketiga, anemia dan persalinan kasep (persalinan lama) merupakan komplikasi yang sering terjadi pada kehamilan remaja (Kusmiran, 2011). Organ reproduksi yang belum matang dapat menyebabkan resiko pada kesehatan fisik dan psikis remaja itu sendiri. Dalam kehamilan ada tahapan yaitu 4T (Terlalu Muda, Terlalu Tua, Terlalu Sering, Terlalu Banyak Anak), oleh karena itu usia yang belum cukup matang tidak diperbolehkan untuk hamil atau menikah sebelum usia yang produktif (Kumalasari, 2012). Dampak lain yang terjadi yaitu psikologi remaja akan terganggu jika melakukan hubungan seksual dengan cara dipaksa atau mengalami kehamilan yang tidak dikehendaki, psikologi remaja sangat berpengaruh terhadap masa depan remaja sehingga harus memiliki pengetahuan yang luas tentang seksual atau kesehatan reproduksi (Nirwana, 2011). Oleh karena itu, dengan pengetahuan yang baik, dan memberikan informasi pada siswa-siswi tentang dampak seks bebas atau pergaulan remaja yang berdampak pada masa depannya dan juga kesehatan reproduksinya dan mengarahkan remaja untuk bergaul dalam hal yang positif 
sehingga remaja tidak

terpengaruh oleh hal yang negatif dan terpengaruh oleh dampak seks bebas, sehingga remaja dapat menjaga diri sendiri dan kesehatan organ reproduksinya.

\section{Kesimpulan}

Pengetahuan remaja tentang dampak seks bebas bagi kesehatan reproduksi sebagian besar memiliki pengetahuan cukup baik sebanyak 32 responden (40\%) dari total 80 responden.

\section{Saran}

Berdasarkan hasil penelitian ini disarankan untuk menyebarluaskan hasil penelitian ini sebagai bahan bacaan bagi mahasiswa kebidanan selanjutnya, disarankan pula agar hasil penelitian ini didapat sebagai referensi ilmiah guna penelitian selanjutnya agar hasil penelitian ini dapat dianggap sebagai masukan untuk menambah wawasan dan meningkatkan pengetahuan penelitian yang akan datang. Bagi institusi kesehatan dapat bekerjasama dengan pihak sekolah untuk memberikan informasi yang lebih baik

\section{Ucapan Terimakasih}

Ucapan terima kasih kami sampaikan kepada pihak yang membantu terlaksananya penelitian ini yaitu SMPN I Plemahan Kabupaten Kediri

\section{Daftar Pustaka}

Bowden Jan \& Vicky Manning. (2011). Promosi Kesehatan Dalam Kebidanan (Prinsip \& Praktik).Terjemah. Jakarta: EGC.

Heriana, E. D. (2012). Memahami Perkembangan Fisik Remaja. Yogyakarta :Gosyen Publishing.

Kumalasari, I \& Iwan, A. (2012). Kesehatan Reproduksi (Untuk Mahasiswa Kebidanan \& Keperawatan). Jakarta. Salemba Medika.

Kusmiran, E. (2011). Kesehatan Reproduksi Remaja Dan Wanita. Jakarta : Salemba Medika.

Nirwana, A. (2011).Psikologi Kesehatan Wanita (Remaja, Menstruasi, Menikah, Hamil, Nifas, Menyusui).Yogyakarta : NuhaMedika. 